\section{A SURVEY OF PAEDIATRICIANS' KNOWLEDGE AND PRACTICES ABOUT INFLUENZA VACCINES IN HIGH RISK GROUPS OF CHILDREN}

\author{
H.F. Ayyash ${ }^{1}$, M.O. Ogundele ${ }^{2}$, M. Babiker ${ }^{1}$ \\ ${ }^{1}$ Dept of Paediatrics, Doncaster and Bassetlaw \\ NHS Foundation Trust, Associated Teaching \\ Hospitals, Doncaster, ${ }^{2}$ Dept of Community \\ Paediatrics, Alder Hey Childrens' Hospital NHS \\ Foundation Trust, Liverpool, UK
}

Aims and background: We aimed to assess paediatricians' awareness of Chief Medical Officer's (CMO) recommendations in relation to influenza vaccination of high risk children in the Trent region of England.

Methods: A questionnaire was posted out to 100 consultant paediatricians. Atotal of 68 questionnaires were returned and analysed.

Results: $41 \%$ and $49 \%$ of the respondents were working in tertiary and district hospitals respectively. $89 \%$ of them claimed to be aware of the CMO's newsletters which listed the high-risk groups of children requiring influenza vaccines.

The highest rates of vaccine recommendation were for children with chronic lung disease (70.5\%), congenital heart disease $(68 \%)$, cystic fibrosis $(66 \%)$, chronic heart failure $(63 \%)$, asthmatics requiring regular steroids (62\%), neuromuscular diseases (59\%), severe splenic dysfunction (59\%), children aged below 5 years with previous invasive pneumococcal disease (56\%), diabetes mellitus $(53 \%)$ and chronic renal failure $(48.5 \%)$.

The lowest rates of vaccine recommendations included nephrotic syndrome (43\%), post renal transplant $(41 \%)$, chronic liver disease (35\%), cirrhosis (26\%), HIVIAIDS (37\%), children on chemotherapy/steroids (38\%), previously admitted for asthma $(22 \%)$ or with a lower respiratory tract disease $(9 \%)$.

Conclusion: Most paediatricians were aware of the $\mathrm{CMO}$ recommendations on influenza vaccines for high risk children. This knowledge however was not always translated into correct advice given to patients in routine clinical practice. We recommend that regular education and training for the busy practising paediatricians should be undertaken to ensure that continual high quality of care is rendered to children who need to be vaccinated with the Influenza vaccine.

\section{6}

\section{A SURVEY OF PAEDIATRICIANS PRACTICES AND KNOWLEDGE ABOUT PNEUMOCOCCAL VACCINES IN HIGH RISK CHILDREN BEFORE THE ERA OF UNIVERSAL IMMUNISATION}

\author{
M.O. Ogundele ${ }^{1}$, H.F. Ayyash², M. Babiker ${ }^{2}$ \\ ${ }^{1}$ Dept of Community Paediatrics, Alder Hey \\ Childrens' Hospital NHS Foundation Trust, \\ Liverpool, ${ }^{2}$ Dept of Paediatrics, Doncaster and \\ Bassetlaw NHS Foundation Trust, Associated \\ Teaching Hospitals, Doncaster, UK
}

Aims and background: We aimed to assess the knowledge and practice of paediatricians in the Trent region of England about the Chief Medical Officer's (CMO) recommendations for the pneumococcal vaccines $(P V)$ to high-risk children before the introduction of the vaccine into the routine universal immunisation programme in Sept 2006.

Methods and Design: Atotal of 68 self-administered questionnaires were returned from a total of 100 posted out to paediatricians in the Trent region.

Results: $89 \%$ of the paediatricians were aware of the CMO's recommendations of pneumococcal and influenza vaccines to high risk children. The most correctly identified high risk groups for PV were children with asplenia / splenic dysfunction (71\%), chronic lung disease (69\%), previous invasive pneumococcal disease $(65 \%)$, congenital heart disease $(63 \%)$, neuromuscular diseases $(59 \%)$, nephrotic syndrome (57\%), cystic fibrosis (54\%) and chronic heart failure (54\%). 